\title{
A Modeling Study of the Climatological Current Field and the Trajectories of Upwelled Particles in the East Australian Current
}

\author{
Moninya Roughan, ${ }^{*}$ Peter R. Oke, ${ }^{+}$and Jason H. Middleton \\ School of Mathematics, University of New South Wales, Sydney, New South Wales, Australia
}

(Manuscript received 22 March 2002, in final form 17 March 2003)

\begin{abstract}
The climatological current field off the coast of New South Wales, Australia, is investigated using results from a field experiment and a diagnostic, numerical modeling study. In particular, the flow dynamics are examined near Smoky Cape $\left(30^{\circ} 55^{\prime} \mathrm{S}\right)$ in the vicinity of the East Australian Current separation point. Modeled velocity fields compare favorably with observed velocity measurements that were obtained in this region during November 1998. An investigation of the role of advection in the alongshore momentum equation reveals that $U V_{x}$ and $V V_{y}$ change sign about the separation point, representing a shift in the flow regime from onshore advection and southward acceleration (north of the separation) to seaward advection and weaker southward currents (south of the separation). Bottom stress increases on the continental shelf downstream of the separation point, coincident with high horizontal divergence throughout the region. South of Smoky Cape, the near-bottom flow is characterized by a low Burger number, coincident with a subcritical Richardson number. These characteristics imply that the timescale in which bottom boundary layer shutdown occurs will be lengthened, enabling a persistent flow of potentially nutrient rich water into the coastal region. A series of Lagrangian particle tracking experiments designed to investigate the fate of the upwelled water are presented. Motivated by an observed chlorophyll- $a$ maximum along the $25.25 \sigma_{\theta}$ isopycnal, water of this density is used as a proxy for nutrient-enriched water. It is found that upwelled water originates at depth to the north of Smoky Cape and at times well offshore. South of Smoky Cape, coastal recirculations are evident, suggesting that upwelled water could be trapped in eddy fields adjacent to the coast and thus explaining why phytoplankton blooms are prevalent in the region south of Smoky Cape.
\end{abstract}

\section{Introduction}

Typically the surface waters on the east coast of Australia are devoid of nutrients. However, in the Smoky Cape region $\left(30^{\circ} 55^{\prime} \mathrm{S}\right)$ climatological records of temperature, salinity, and nutrients show a region of preferential uplift and nutrient enrichment (Roughan and Middleton 2002). Persistent upwelling that is seemingly unrelated to local wind forcing has been observed to the south of Smoky Cape (Rochford 1975). These upwellings frequently result in sharp thermal fronts over the continental shelf (e.g., Godfrey et al. 1980; Cresswell et al. 1983; Oke et al. 2003) and are associated with sporadic blooms of phytoplankton and zooplankton (Hallegraeff and Jeffrey 1993). In oligotrophic waters

\footnotetext{
* Current affiliation: Scripps Institution of Oceanography, University of California, San Diego, La Jolla, California.

+ Current affiliation: CSIRO Marine Research, Hobart, Tasmania, Australia.
}

Corresponding author address: Moninya Roughan, Scripps Institution of Oceanography, UCSD, 9500 Gilman Drive, La Jolla, CA 92093-0218.

E-mail: mroughan@ucsd.edu the consequences of an increase in primary production are evident throughout the food chain. Figure 1 shows a typical satellite image of sea surface temperature (SST) and a SeaWifs image of chlorophyll $a$ on the east coast of Australia. Clearly evident is a cooler patch of water south of both Cape Byron and Smoky Cape. Associated with this cooler water is an increase in chlorophyll $a$. Although the maximum chlorophyll- $a$ concentration $\left(3.5 \mu \mathrm{mol} \mathrm{L}{ }^{-1}\right)$ is lower than those found in prolific upwelling regions, such concentrations are significant in these oligotrophic coastal waters.

An idealized modeling study by Oke and Middleton (2000) demonstrated the feasibility of persistent upwelling driven by the East Australian Current (EAC) south of Cape Byron. Subsequently, in an observational study by Roughan and Middleton (2002), current driven upwelling was directly observed in the Smoky Cape region. Both locations are typified by the narrowing of the continental shelf at the headland and regular upwelling. The specific aims of this study are to gain insight into the nature of the typical three-dimensional velocity fields associated with the climatological values of temperature and salinity on the New South Wales (NSW) shelf and in the adjacent Tasman Sea, to investigate the flow dynamics about the separation point of 

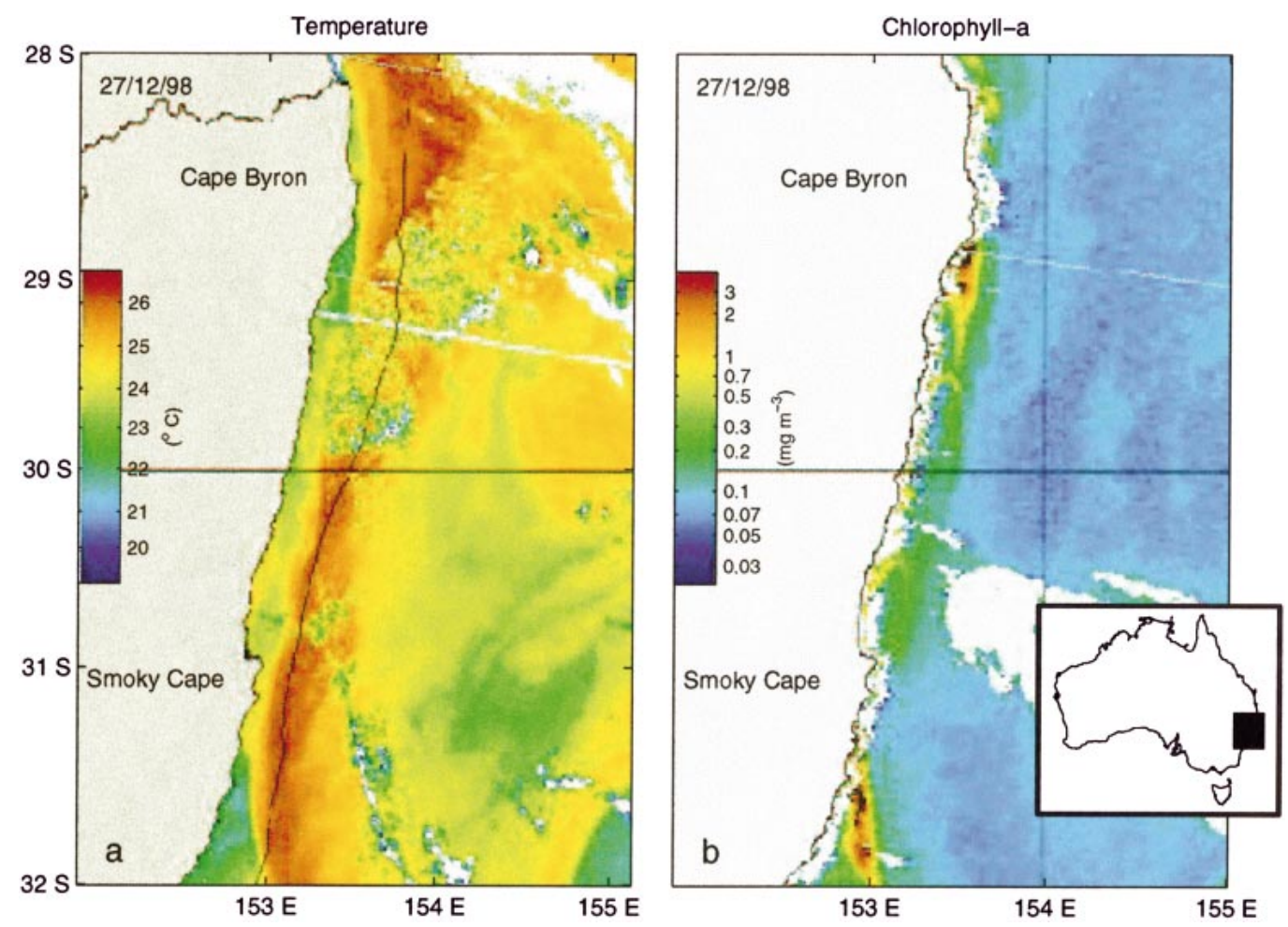

FIG. 1. (a) AVHRR image of sea surface temperature and (b) SeaWifs image of chlorophyll $a$ off the east coast of Australia. Note the decrease in temperature and the increase in chlorophyll $a$ south of Cape Byron and Smoky Cape.

the EAC, and to address the question of "the origin of upwelled water."

In this study, a new high-resolution $\left(1 / 2^{\circ}\right)$ climatology of both temperature and salinity is used to initialize a numerical model in order to investigate the three-dimensional velocity fields in the Smoky Cape region. The model configuration is described in section 2. In section 3 an analysis of the modeled velocity fields and a comparison with observed current velocities from an acoustic Doppler current profiler (ADCP) survey, combined with hydrographic data is presented. In section 4 the flow dynamics about the separation point of the EAC are examined in detail using the velocity fields obtained from the model simulation with particular emphasis on the predisposition of the Smoky Cape region to regular upwelling. Last, a series of offline Lagrangian particle tracking experiments are run to investigate the possible origin and fate of upwelled "particles" (section 5). A summary of key findings is presented in section 6 .

\section{Model configuration}

This study utilizes the Princeton Ocean Model $(\mathrm{POM})$, which is a three-dimensional, nonlinear, primitive equation model (Blumberg and Mellor 1987; Mellor 1996). The specific POM configuration that is applied here for the NSW shelf region is derived from a configuration that has been applied successfully on sev- eral previous occasions (Gibbs et al. 1997; Marchesiello et al. 2000; Oke and Middleton 2001).

The model domain extends from $28.5^{\circ}$ to $37.5^{\circ} \mathrm{S}$ and from $150^{\circ}$ to $157.5^{\circ} \mathrm{E}$. The horizontal curvilinear grid has across-shore spacings that increase from $2.5 \mathrm{~km}$ at the coast to $16 \mathrm{~km}$ at the eastern boundary and alongshore grid spacings ranging from 6 to $22 \mathrm{~km}$ (Fig. 2). The minimum and maximum depths are 15 and 2000 $\mathrm{m}$, respectively.

At the southern and eastern boundary, a combination of radiation, zero gradient, and relaxation conditions are implemented as described by Gibbs et al. (1997). The conditions at the northern boundary are clamped to their initial values and a free-slip, no-flux condition is implemented at the coastal (western) boundary. One limitation of this configuration is the propagation of coastal trapped waves at a clamped boundary.

The model is initialized using climatological data of temperature and salinity obtained from the Commonwealth Scientific and Industrial Research Organization (CSIRO) Atlas of Regional Seas (CARS) as described by Ridgway et al. (2002). The raw data, which consist of temperature, salinity, nitrate, phosphate, silicate, and dissolved oxygen, are interpolated onto a uniform grid to $1 / 2^{\circ}$ resolution. Vertically the atlas has 56 (unequal) depth layers from 0 to $5500 \mathrm{~m}$, with maximum resolution in the top $300 \mathrm{~m}$. The EAC has a strong periodic cycle that is captured in CARS through the use of semi- 


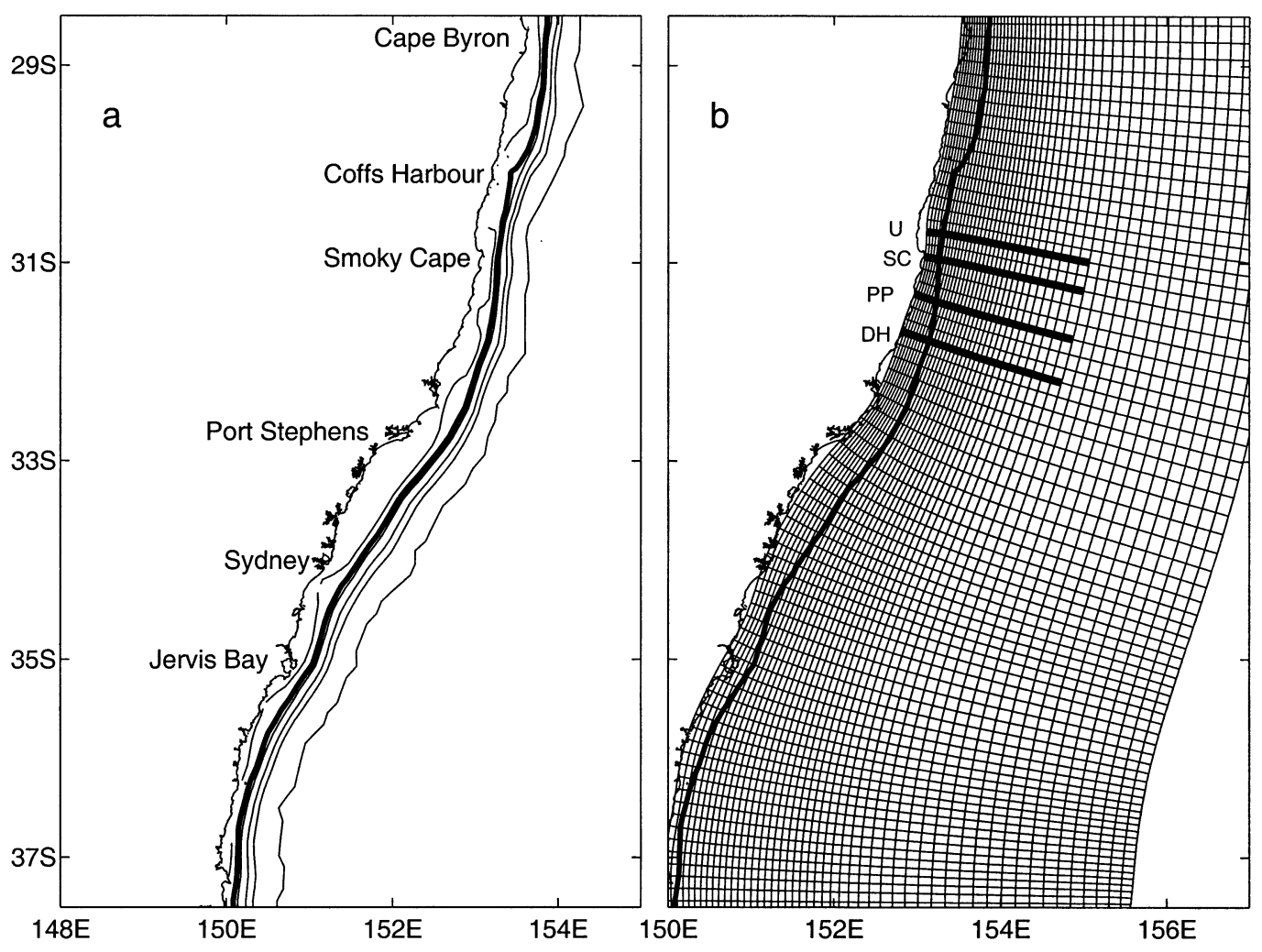

FIG. 2. The location of the study area on the NSW shelf. (a) The topography of the coast and the bottom bathymetry and (b) the model grid. Isobaths marked are 100, 200, 500, 1000, 1500, and $2000 \mathrm{~m}$ (the 200-m isobath is in bold). The across-shore grid spacing increases from $2.5 \mathrm{~km}$ at the coast to $16 \mathrm{~km}$ at the eastern boundary. Alongshore the grid spacing ranges from 6 to $22 \mathrm{~km}$. Also marked are the four sections where observations were taken during Nov 1998. From north to south: Urunga (U), Smoky Cape (SC), Point Plomer (PP), and Diamond Head (DH).

annual harmonics; however, in this application only the mean fields are used. The climatological temperature and salinity fields are interpolated linearly onto the model grid and density is calculated using the nonlinear equation of state (Mellor 1991). The initial velocity field is at rest and the effective horizontal density gradients implemented in the momentum equations are ramped up from zero to their values (as prescribed by CARS) over five inertial periods.

The model is forced at the northern boundary with a geostrophic current and sea level elevation. The geostrophic velocities are calculated from the CARS climatology of temperature and salinity assuming a level of no motion of $2000 \mathrm{~m}$, which is standard practice for the EAC region (Gibbs et al. 1997; Marchesiello et al. 2000). In support of this, observations have shown that currents below 2000-m depth are typically small and incoherent with surface currents (Boland and Hamon 1970). Over the continental shelf where the depth is shallower than $2000 \mathrm{~m}$, the geopotential anomalies are calculated using the extrapolation technique of Reid and Mantyla (1976). Figure 3 shows the density field at the northern boundary and the alongshore and across-shore geostrophic currents used to force the model, which are also ramped over five inertial periods.
The model is then run diagnostically for 20 days, where the temperature and salinity fields are constrained to their initial conditions, whilst the surface elevation $(\eta)$ and the velocity field, (with across-shore, alongshore and vertical components denoted by $u, v$, and $w$, respectively) are allowed to adjust to the density field with time. After about 12 days the fluctuations in the energy fields are minimal demonstrating that a quasi-steady state has been reached. In this idealized investigation of the mean current field associated with the climatological values of temperature and salinity, external surface forcings such as heat flux, freshwater, or wind stress terms are not imposed.

\section{Model circulation and model-data comparisons}

To ensure that an appropriate representation of the climatological velocities is obtained, once the model has reached quasi equilibrium the modeled fields are averaged over a 5-day period from day 12.5 to 17.5 , (i.e., a 5-day average centered on day 15).

\section{a. The barotropic fields}

The barotropic fields are presented in Fig. 4. The depth averaged velocity field (Fig. 4a) shows a dominant 


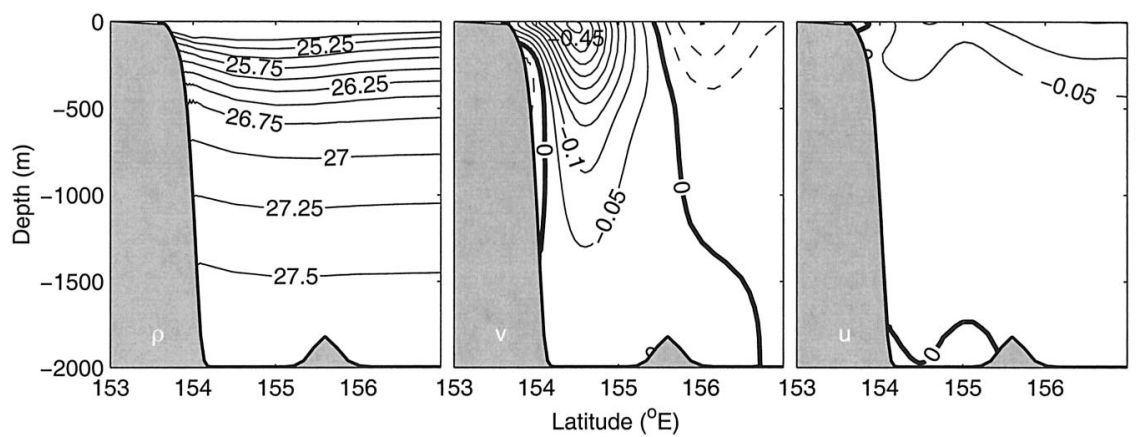

FIG. 3. The forcing fields imposed at the northern boundary. The density field $(\rho)$ calculated from the CARS data, [contour interval $(\mathrm{CI})=0.25 \mathrm{~kg} \mathrm{~m}^{-3}$ ] and the alongshore $(v)$ and acrossshore $(u)$ geostrophic velocities calculated from the geopotential anomalies $\left(\mathrm{CI}=0.05 \mathrm{~m} \mathrm{~s}^{-1}\right)$. The maximum alongshore velocity is $0.45 \mathrm{~m} \mathrm{~s}^{-1}$ southward, and positive velocities are indicated by the dashed contours.

southward flowing jet extending down the east coast of NSW. The current flows adjacent to the continental shelf to Smoky Cape $\left(30^{\circ} 55^{\prime} \mathrm{S}\right)$ and then separates from the coast. The current continues due south, whereas the coastal orientation bends away in a southwesterly direction. The depth-averaged current speeds are up to 2 $\mathrm{m} \mathrm{s}^{-1}$ in the center of the southward jet.

Inshore of the jet there is a weak northward flow adjacent to the coast between Port Stephens and Smoky Cape. Just to the north of Port Stephens the current tends to bifurcate forming a broader jet that bends eastward and a narrower jet that extends southward along the coast. Both these scenarios have been observed separately in the EAC (Roughan and Middleton 2002), how- ever, at times this bifurcation is also evident. Observations show that when the main axis of the current bends eastward the remaining alongshore flow is generally weaker (Tilburg et al. 2001) but that when the current remains attached to the coast the alongshore flow remains strong.

The sea surface elevation is shown for the Smoky Cape region in Fig. 4b. There is a region of higher elevation to the east of the jet and the jet is strongest where the slope in elevation is the greatest. Across the shelf at Smoky Cape the change in sea level elevation between the 50 - and the $100-\mathrm{m}$ isobath is $2 \mathrm{~cm}$ and between the $100-\mathrm{m}$ isobath and the shelf break (the 200$\mathrm{m}$ isobath) the difference is $7.5 \mathrm{~cm}$. Downstream at
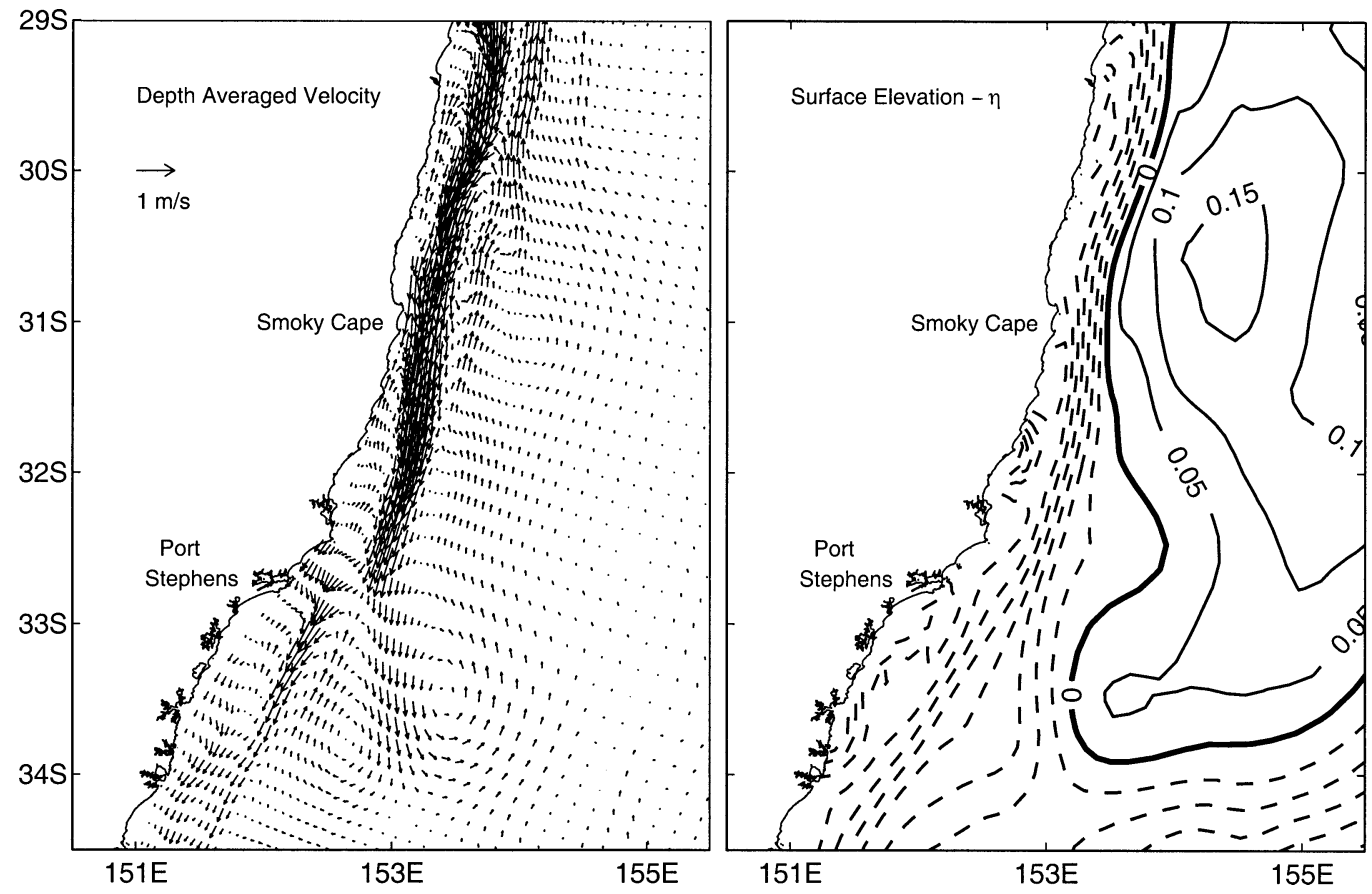

FIG. 4. (a) The depth-averaged velocity field and (b) the sea surface elevation $\eta$. 


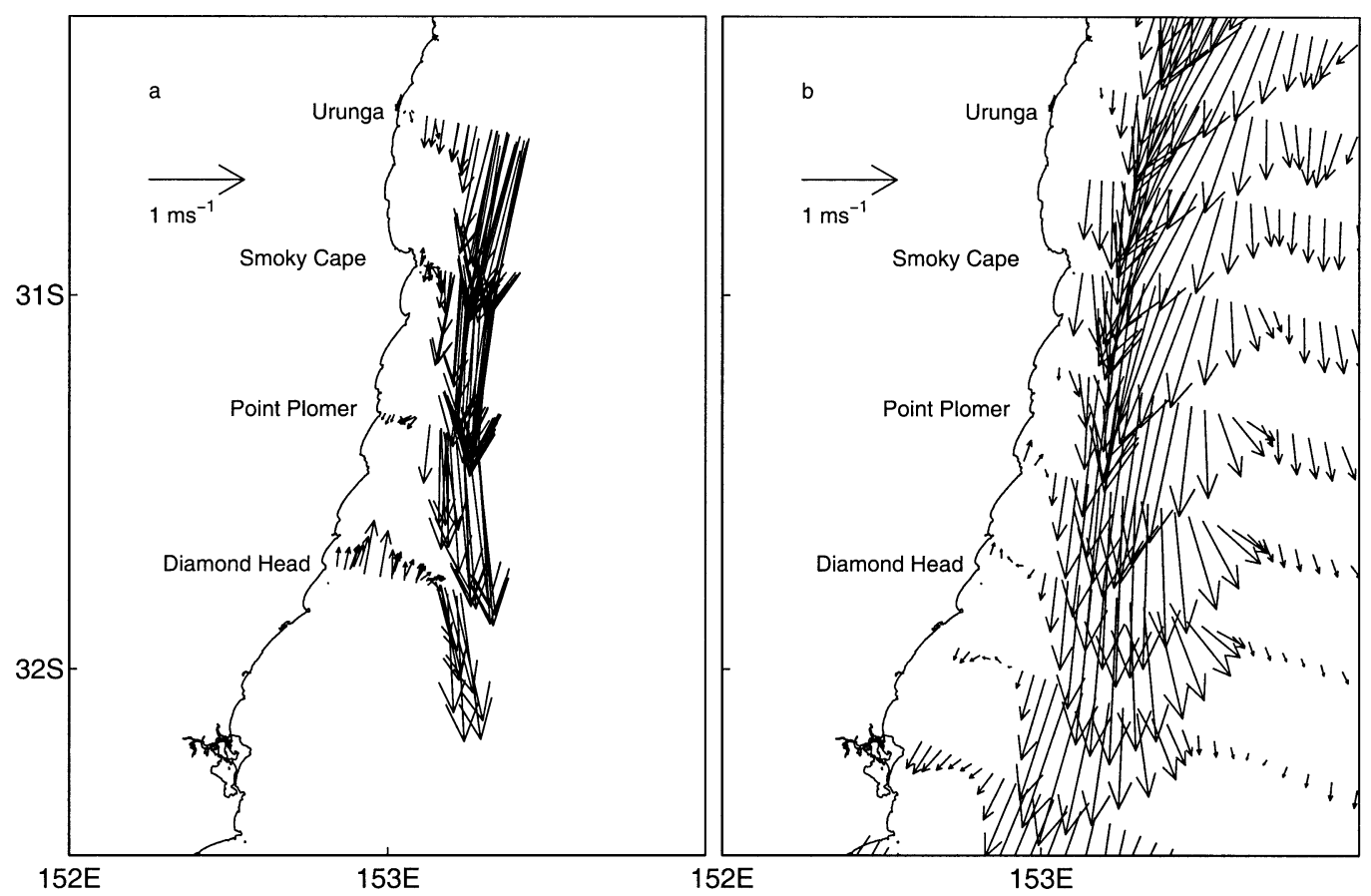

FIG. 5. Comparison of near-surface velocities obtained from (a) ADCP measurements along the four observational transects shown in Fig. 2 and (b) the model.

Diamond Head $\left(31^{\circ} 44^{\prime} \mathrm{S}\right)$, the simulations show a northward flow indicating that the across-shore pressure gradient is in the opposite direction. The sign of the gradient changes between the coast and the 50-m isobath and the difference in elevation is small $(\sim 0.5 \mathrm{~cm})$; from the $50-\mathrm{m}$ isobath to the shelf break the height is almost constant $(3-3.5 \mathrm{~cm})$.

Transport in the EAC has been measured on a number of occasions and the results are quite varied. The most recent transport estimates come from the World Ocean Circulation Experiment (WOCE) PCM3 current meter array positioned at $30^{\circ} \mathrm{S}$, where, over a three year period, Mata et al. (2000) observed mean transports of $22.1 \pm$ $30 \mathrm{~Sv}\left(1 \mathrm{~Sv} \equiv 10^{6} \mathrm{~m}^{3} \mathrm{~s}^{-1}\right)$ toward the south. Others have reported transports of 22-35 Sv southward, between the coast and $155^{\circ} \mathrm{E}$ (Ridgway and Godfrey 1994). Here the transport streamfunction $\left(\psi=\int v d x\right)$ is calculated eastward from the coast across the domain giving a maximum transport of $33 \mathrm{~Sv}$ in this region, which is consistent with previous observations.

\section{b. Near-surface velocities}

The simulated near-surface velocities are shown in Fig. 5 along with observed currents obtained from a shipboard ADCP survey during November 1998 (Roughan and Middleton 2002). Although the model simulation is not an attempt to hindcast observations, both the magnitude and direction of the observed and modeled currents are remarkably consistent. Both show strong southward flow at the shelf break and a tendency for a weaker northward flow near the coast. Additionally both show a weak onshore component north of Smoky Cape and an offshore component farther south. The jet is within close proximity of the coast at Smoky Cape and moves slightly offshore at Diamond Head. This indicates that the separation point of both the observed and modeled EAC lies between Smoky Cape and Diamond Head. The strongest coastal current in the simulation is immediately south of Smoky Cape, perhaps indicating a convergence of the current as the continental shelf narrows, as proposed by Oke and Middleton (2001). Inshore of the strongest southward current is a slight northward flow, which is underestimated by the model at the southern extent of the survey line (Diamond Head). This qualitative agreement between the observations and the simulations demonstrates that the modeled circulation is in fact representative of the realistic circulation in the EAC region.

\section{c. Velocity cross sections}

Figure 6 compares observed and modeled velocities across two sections. The first section, seaward of Smoky Cape, shows a narrow jet in close proximity to the coast. The second section, seaward of Diamond Head, shows the jet centered farther offshore. At both locations the model has realistically depicted the position of the jet over the shelf, the direction of the flow and the strength of the jet. At Smoky Cape both the observations and the model show the core of the jet to be approximately $20 \mathrm{~km}$ offshore with a maximum southward velocity in 


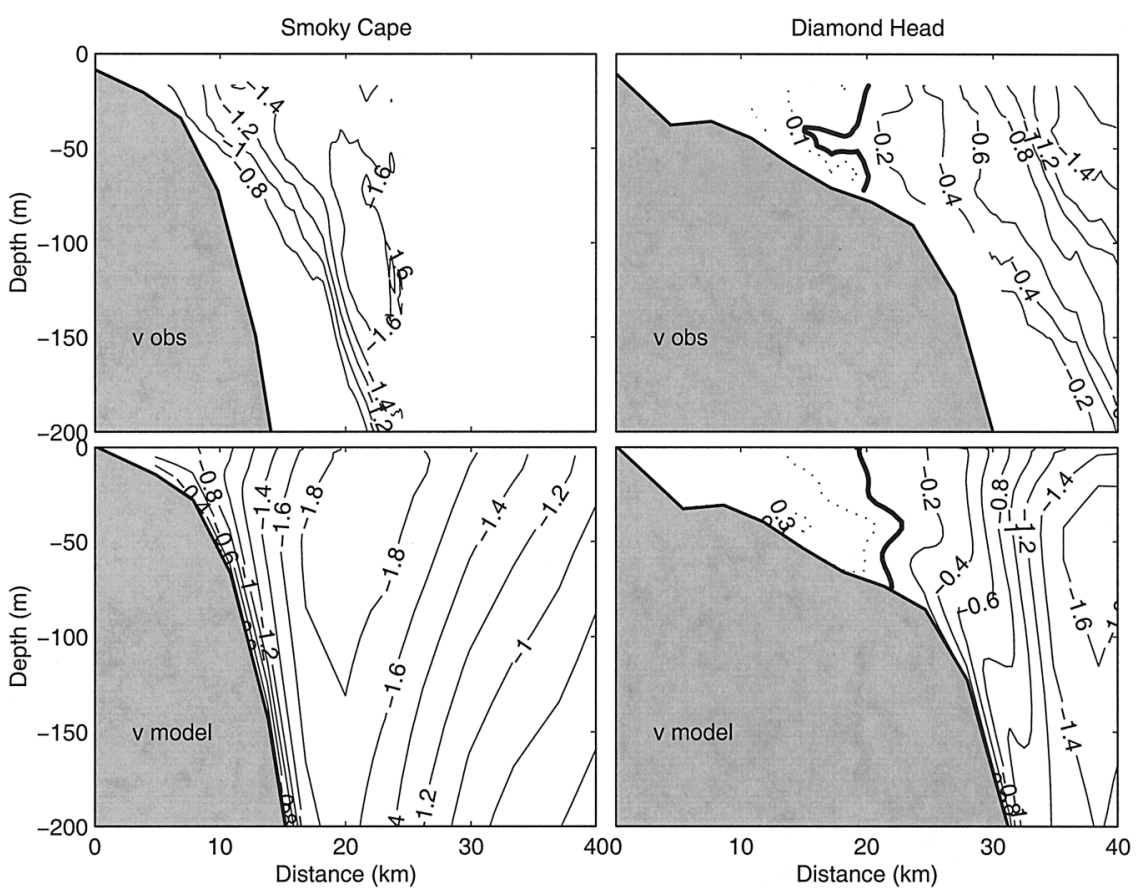

FIG. 6. Comparisons of the (top) observed and (bottom) modeled alongshore currents upstream (Smoky Cape) and downstream (Diamond Head) of the EAC separation point. The solid line represents negative (poleward) alongshore flow, the dotted line represents positive (equatorward) alongshore flow, and the thick solid line represents the zero velocity contour.

excess of $1.6 \mathrm{~m} \mathrm{~s}^{-1}$. Within $10 \mathrm{~km}$ of the coast the flow is directed southward, with speeds of up to $0.8 \mathrm{~m} \mathrm{~s}^{-1}$. The modeled and observed fields differ in the vertical extent and baroclinicity of the jet. In the simulation the core of the jet extends to a greater depth and the velocity is more barotropic along the front. The observations show a velocity of $1 \mathrm{~m} \mathrm{~s}^{-1}$ below the core of the jet, at a depth of $200 \mathrm{~m}$ whereas the simulation shows a maximum velocity of $1.6 \mathrm{~m} \mathrm{~s}^{-1}$ at this depth. The weaker current at depth results in a more gentle gradient across the observed velocity front.

Downstream of the separation point off Diamond Head, a northward countercurrent forms inshore of the main jet. The strength of this northward flow is up to $0.3 \mathrm{~m} \mathrm{~s}^{-1}$ at $10 \mathrm{~km}$ from the coast. The point of zero velocity, located at about $20 \mathrm{~km}$ from the coast is consistent in both the observed and the modeled fields (solid line Fig. 6). Again the position of the jet is depicted realistically ( $\sim 40 \mathrm{~km}$ from the coast); however, the strength of the modeled jet $\left(1.6 \mathrm{~m} \mathrm{~s}^{-1}\right)$ is slightly higher than the observed current $\left(1.4 \mathrm{~m} \mathrm{~s}^{-1}\right)$. In both the modeled and observed fields, the jet weakens and broadens after the current separates from the coast. Eastward of the jet is a northward return flow (Fig. 4a), which has been seen in many earlier observational studies (Ridgway and Godfrey 1997).

The modeled alongshore, across-shore and vertical currents for four cross sections are shown in Fig. 7. The locations of the cross sections are shown in Fig. 2: namely, Urunga, Smoky Cape, Point Plomer, and Diamond
Head. Of interest is the strengthening and weakening of the current as it moves southward. At Urunga the maximum alongshore velocity is $1.8 \mathrm{~m} \mathrm{~s}^{-1}$. As the current moves farther south, the jet tightens at Smoky Cape and accelerates, to a maximum speed of $1.9 \mathrm{~m} \mathrm{~s}^{-1}$ at Point Plomer. The actual core of the current is now subsurface with the maximum alongshore velocity found at a depth of $50 \mathrm{~m}$, located directly above the shelf break. Farther to the south at Diamond Head, the jet weakens slightly as it widens, with the maximum alongshore velocity remaining subsurface with a speed of $1.6 \mathrm{~m} \mathrm{~s}^{-1}$. Observations of a subsurface velocity maximum have been made previously in this region (Cresswell 2000, personal communication; Roughan and Middleton 2002) and this maximum is evident in Fig. 7.

At Urunga and Smoky Cape the across-shore component of the current is predominantly onshore at the shelf break, with a maximum of $\sim 0.5 \mathrm{~m} \mathrm{~s}^{-1}$. This onshore flow weakens moving southward to Diamond Head downstream of the separation point, where the across-shore flow component is predominantly offshore. Inshore of the jet there is a slight eastward flow at the two northern most sections, associated with the tightening of the front. Downstream of the separation at Diamond Head, the inshore flow is directed northward and onshore. This creates a divergence and positive vertical velocities of up to $0.003 \mathrm{~m} \mathrm{~s}^{-1}$ at the shelf break. Inshore of the jet at Smoky Cape, at a depth of $50 \mathrm{~m}$ there is a small vertical velocity of $0.001 \mathrm{~m} \mathrm{~s}^{-1}$, which has the potential to uplift water by approximately $86 \mathrm{~m}$ 

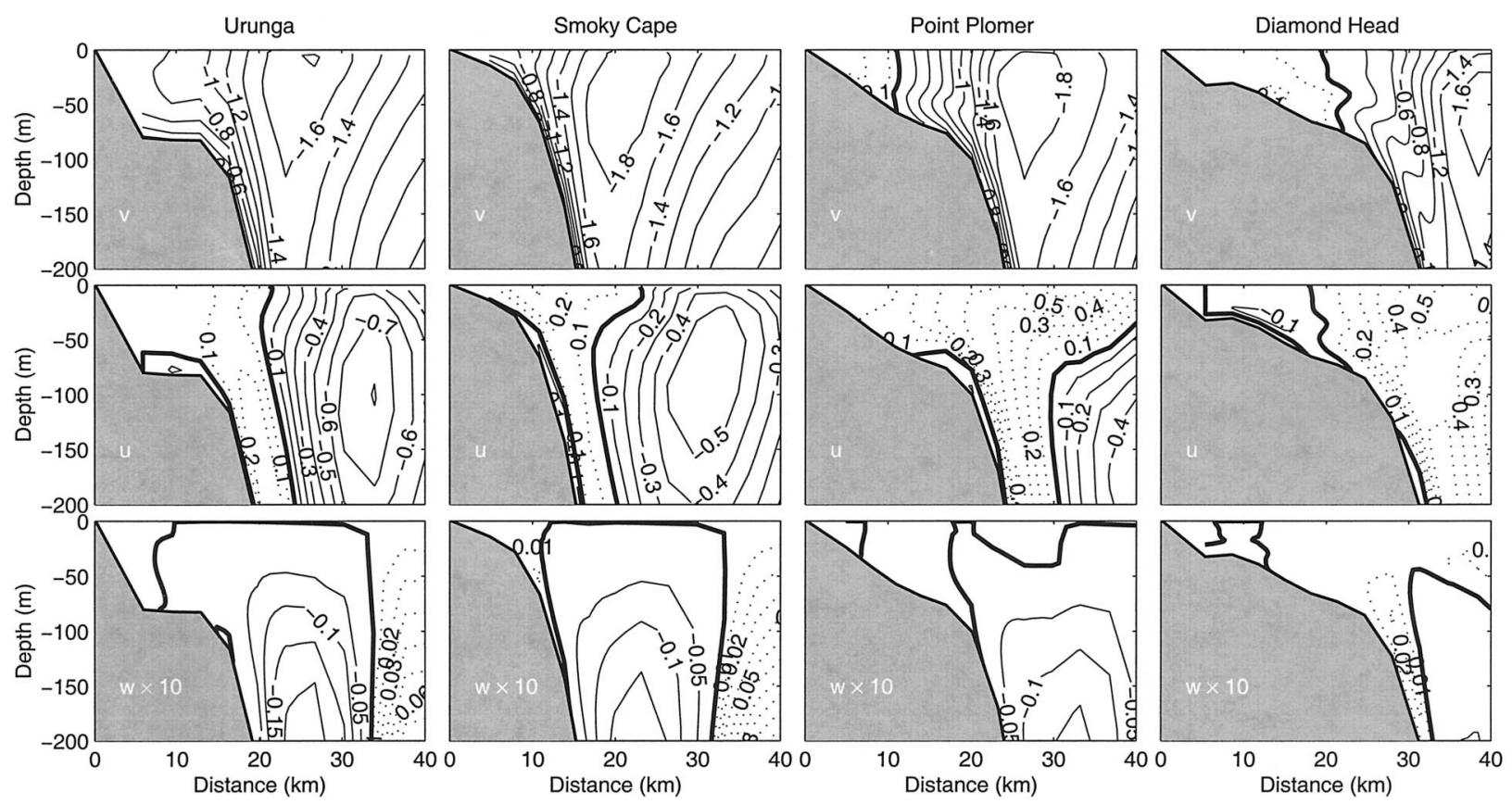

Fig. 7. Cross sections of the climatological currents $(v, u, w)$ obtained from the model $\left(\mathrm{m} \mathrm{s}^{-1}\right)$, at Urunga, Smoky Cape, Point Plomer, and Diamond Head. (As in Fig. 6, solid is negative, dotted is positive, and thick solid is the zero velocity contour.)

per day. In a nutrient-poor environment, this uplifting of deeper and presumably nutrient laden waters to the euphotic zone is biologically significant.

\section{Flow dynamics}

\section{a. Dynamical balances}

An analysis of the depth-averaged alongshore momentum equation is presented to investigate the relative importance of advection, bottom stress and geostrophy. The analysis provides insight into the different dynamics acting on the continental shelf upstream (north) and downstream (south) of the EAC separation point. The depth-averaged alongshore momentum equation is

$$
\begin{aligned}
& V_{t}+U V_{x}+V V_{y}+f U+\mathrm{PG}-\mathrm{SS}+\mathrm{BS} \\
& \quad+\mathrm{HD}=0,
\end{aligned}
$$

where $U$ and $V$ are the depth-averaged currents in the $x$ (across-shore) and $y$ (alongshore) directions, respectively; $V_{t}$ is the tendency term; $U V_{x}$ and $V V_{y}$ are the components of advection; $\mathrm{PG}$ is the alongshore pressure gradient; SS is the surface stress; BS is the alongshore component of bottom stress; and HD is the horizontal diffusivity.

These terms are diagnosed over a 5-day average during the model simulation and the results are shown in Fig. 8 for the Smoky Cape region; SS is not shown as no surface fluxes are applied ( $\mathrm{SS}=0$ ). Physically HD lacks meaning in a sigma-coordinate model as mixing occurs along sigma levels; however, HD is included in the model to aid damping of numerical noise (Blumberg and Mellor 1987) and is included here for completeness. That HD $\neq 0$ is intuitive as it depends on horizontal gradients in velocity (Smagorinsky 1963) which are large in this region. Across the domain $V_{t} \simeq 0$ indicating that the model has reached quasi equilibrium, which is desirable for an analysis of the mean velocity fields.

In order to assess the relative magnitudes of the alongshore and across-shore advection components we present these components explicitly, however, because of the sensitivity of $U$ to the grid orientation, we note that the separation of the horizontal advection term into its two components introduces uncertainties into $U V_{x}$. By contrast, $V V_{y}$ is relatively insensitive to the grid orientation. With this uncertainty noted, we find that separation of these components provides more insight into the underlying dynamics in comparison with an analysis that considers only the sum of the pair.

From Fig. 8 it is evident that there is a distinct shift in the dynamics about the EAC separation point. This is demonstrated by a change in the flow regime from onshore funnelling $(f U>0)$ upstream of the separation point to offshore velocities $(f U<0)$ downstream of the separation point; $U V_{x}$ has a positive maximum immediately onshore of the core of the EAC jet which overlies the shelf break upstream of the separation point, consistent with the EAC being advected toward the coast. This corresponds with a negative maximum in $V V_{y}$, consistent with the alongshore flow accelerating to the south in a Lagrangian sense over the continental shelf as demonstrated by Oke and Middleton (2001).

Well upstream and downstream of the separation point $f U$ and $\mathrm{PG}$ tend to be opposite in sign at the shelf 


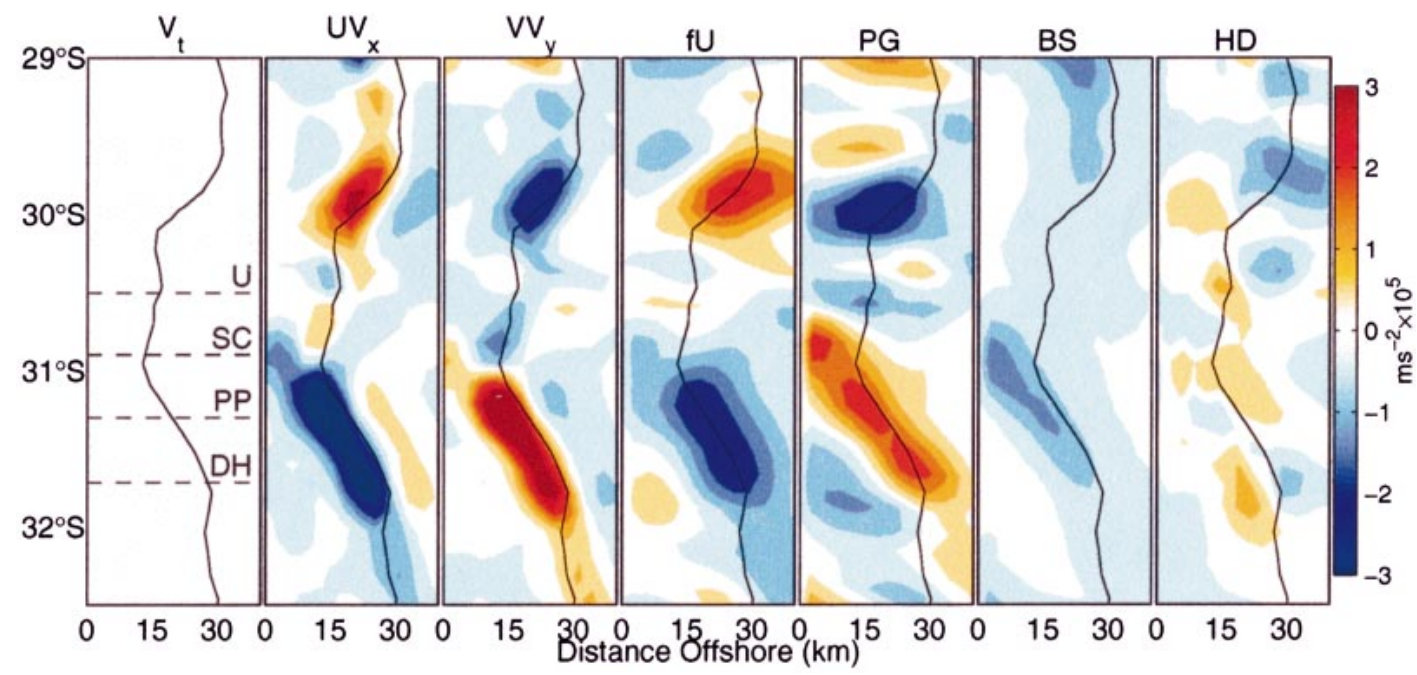

FIG. 8. From left to right the terms in the depth-averaged alongshore momentum equation are tendency $\left(V_{t}\right), u$ component of advection $\left(U V_{x}\right), v$ component of advection $\left(V V_{y}\right)$, Coriolis $(f U)$, pressure gradient (PG), bottom stress (BS), and horizontal diffusion (HD). The geometry of the figure is depicted with axes being distance offshore from the coast (km) and latitude, and the solid irregular line from top to bottom in each frame depicts the 200-m isobath indicating the shelf break.

break. At Urunga immediately to the north of Smoky Cape both $f U$ and PG become small and negative indicating an ageostrophic component to the alongshore flow as the current approaches the narrow continental shelf at Smoky Cape. At this point the slope in PG changes from negative to positive indicating a sea-level maximum at Smoky Cape and a downstream depression in elevation, which would contribute to upwelling south of the separation point.

About the separation point itself (immediately south of Smoky Cape) $f U$ and $U V_{x}$ are small indicating that the flow is primarily shore parallel. At the shelf break $V V_{y}$ increases in magnitude together with an increase in BS. In the midshelf region immediately south of Smoky Cape, BS is a negative maximum indicating onshore flow, and this is consistent with the increase in BS observed in this region by Roughan and Middleton (2002, 2003) which resulted in a persistent current driven upwelling.

South of the separation point, $U V_{x}$ and $V V_{y}$ change sign, representing a shift in the flow regime from onshore advection and southward acceleration (north of the separation) to seaward advection and weaker southward currents (south of the separation). This suggests that nonlinear advection plays a role in the separation of the EAC from the coast, as demonstrated by Marchesiello and Middleton (2000).

As the current separates, initially vortex stretching occurs and the vorticity $\left(\propto V V_{y}\right)$ increases. Vortex stretching will serve to tighten the front enhancing strong horizontal $\left(\propto U V_{x}\right)$ and vertical velocity shear. However, there comes a point when decoupling occurs and velocity is no longer constrained by contours of $f / H$. It is then that the vorticity decreases again, and the core of the current weakens and widens. The expansion of the jet is seen in the depthaveraged velocity vectors of Fig. 4, and the velocity cross sections upstream and downstream of the EAC separation point shown in Fig. 6.

Calculations of the terms in the across-shore momentum equation (not shown) reveal that $-f V$ is more than an order of magnitude greater than the nonlinear terms at each location demonstrating the dominance of geostrophy in the across-shore direction as expected.

\section{b. Divergence and convergence}

The region's predisposition to upwelling is examined further through calculations of the flow divergence (convergence) at the surface (Fig. 9). Divergence is high seaward of the jet; of interest, however, divergence is also high within close proximity of the coast and across the entire continental shelf south of $32^{\circ} \mathrm{S}$, indicated by the shaded regions in Fig. 9. This positive divergence maximum inshore of the jet and south of the separation point implies the existence of upwelling in the region. The maximum divergence is $6.8 \times 10^{-5} \mathrm{~s}^{-1}$ along the surface slab. The amount of upwelled water resulting from this divergence can be calculated for a given volume. Assuming a slab of water (such as the surface slab) to be $20 \mathrm{~m}$ thick across an area of $1 \mathrm{~km}^{2}$, then the amount of water upwelled would be in the range of 1340-1440 $\mathrm{m}^{3} \mathrm{~s}^{-1}$ across the slab. This is derived from an upwelling velocity of $0.0013-0.0014 \mathrm{~m} \mathrm{~s}^{-1}\left(110-120 \mathrm{~m} \mathrm{day}^{-1}\right)$, which is comparable to the vertical velocities obtained from the model. Regions of convergence occur along the shelf break where $\partial u / \partial x$ is the greatest indicating a narrowing of the jet. In theory geostrophic flow is nondivergent. In this region both divergence and conver- 


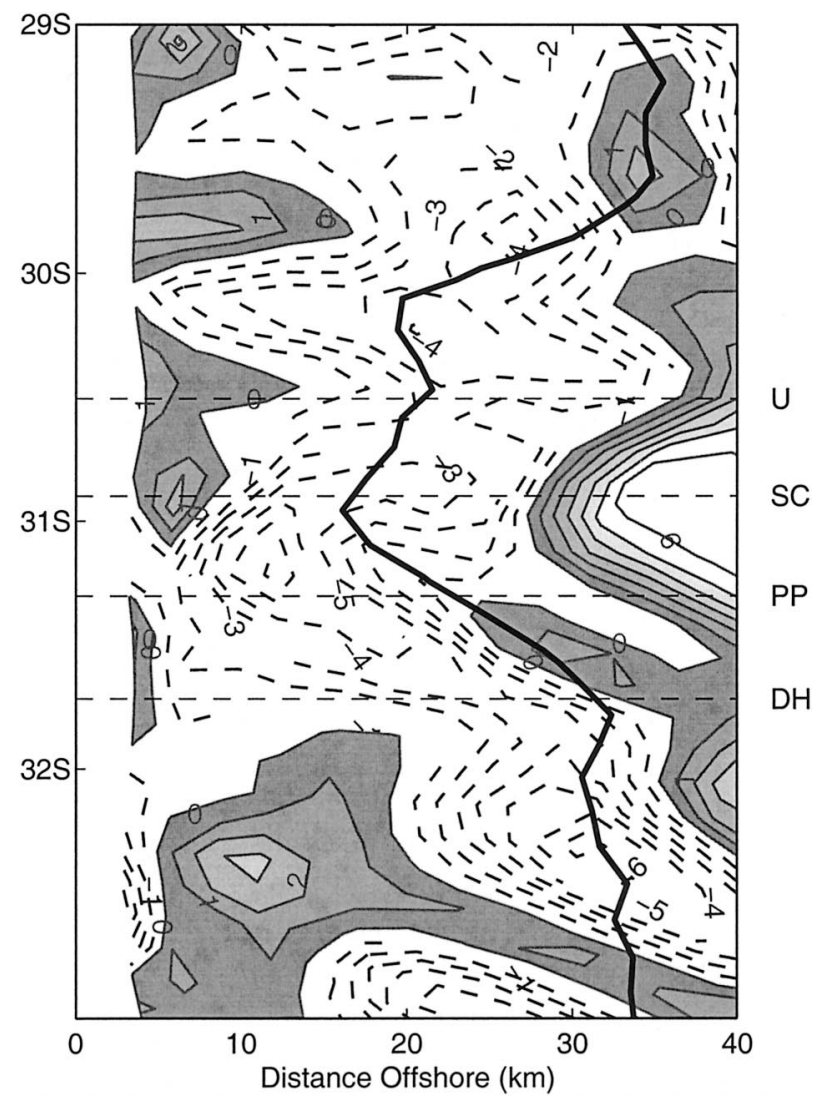

FIG. 9. Divergence and convergence at the surface $\left(\mathrm{CI}=1 \times 10^{5}\right.$ $\mathrm{s}^{-1}$ ). Shaded contours represent divergence, the dashed contours represent convergence; and the horizontal dashed lines represent the four transects, Urunga, Smoky Cape, Point Plomer, and Diamond Head. The geometric depiction is as in Fig. 8. Close to the coast data are unavailable for these calculations, and the field is left blank.

gence are prevalent again indicating the ageostrophic nature of the flow about the separation point of the EAC.

\section{c. The bottom boundary layer}

The nondimensional parameters that are relevant indicators of bottom boundary layer (BBL) activity are the gradient Richardson number, $\mathrm{Ri}=N^{2} /\left(u_{z}^{2}+v_{z}^{2}\right)$, and the Slope Burger number, $B_{u} \approx N^{2} / \alpha^{2} f^{2}$; where $N$ is the buoyancy frequency, $\alpha$ is the bottom slope, $f$ is the Coriolis parameter, and the subscripts denote vertical derivatives. When $\mathrm{Ri}<0.25$ the flow is expected to be turbulent and when combined with a small value of $B_{u}$, shoreward Ekman pumping through the BBL is permitted for an extended period of time which could eventually result in upwelling of slope waters to the surface. This occurs because the BBL shut down timescale: $\tau_{s}$ $=1 / B_{u}^{2} f^{2}$ increases as $B_{u}$ decreases (Garrett et al. 1993).

Roughan and Middleton (2003) noted that during a current driven upwelling event the value of $B_{u}$ obtained from observations between Smoky Cape and Diamond Head decreased in midshelf regions. In an idealized modeling study of EAC driven upwelling off central eastern Australia, Oke and Middleton (2000) demonstrated that persistent upwelling coincided with regions of low $B_{u}$ and Ri. Additionally, Godfrey et al. (1980) observed flow with low Ri above the continental shelf off Cape Byron. Here near-bottom values of $\mathrm{Ri}$ and $B_{u}$ are calculated across the model domain (Fig. 10). Immediately south of Smoky Cape there is a region extending between Point Plomer and Diamond Head where low $\mathrm{Ri}$ values coincide with low $B_{u}$. It is here that the bottom slope is more gradual (small $\alpha$ and therefore small $B_{u}$ ), and mixing is high (low Ri), thus facilitating movement of water shoreward through the BBL. This is consistent with the idea that nonlinear acceleration of the flow near Smoky Cape enhances upwelling farther to the south.

The comparison of observed and simulated fields has shed further light on the nonlinear processes that occur in the Smoky Cape region. That nonlinearities and current driven upwelling are seen in the climatological current fields implies that these are persistent features along the coast between Smoky Cape and Diamond Head, thus explaining the commonly observed surface nutrient plumes in the region (Rochford 1975; Hallegraeff and Jeffrey 1993).

\section{Lagrangian particle tracking experiments}

A series of offline particle tracking experiments are conducted using the average climatological current field derived from the model to quantify meridional pathways and timescales of spreading within the EAC system. The experiments are conducted to address the question: Where does the water come from? Specifically, where do upwelled waters originate in a three-dimensional sense (i.e., depth and position) and once upwelled where do surface waters move to? In order to answer these biologically important questions particles are advected backward in time from their final position.

\section{a. Chlorophyll-a concentrations and the $25.25 \sigma_{\theta}$ isopycnal}

The $25.25 \sigma_{\theta}$ isopycnal surface is chosen for a series of along-isopycnal particle-tracking experiments enabling examination of the potential advection of nutrient and planktonic organisms in a three-dimensional sense. This choice was made on the basis of an observed relationship between density and chlorophyll- $a$ concentrations. Figure 11 shows the average density and chlorophyll- $a$ concentrations from a number of CTD casts obtained between the coast and $40 \mathrm{~km}$ offshore, in the depth range of 25-1000 $\mathrm{m}$ along four transects off the NSW coast measured during November 1998 (Roughan and Middleton 2002). Mean concentrations are a maximum at the northern extent of the survey $\left(2.6 \mathrm{mg} \mathrm{m}^{-3}\right)$ and generally decrease toward the south. Maximum concentrations, however, were highest at Point Plomer (im- 

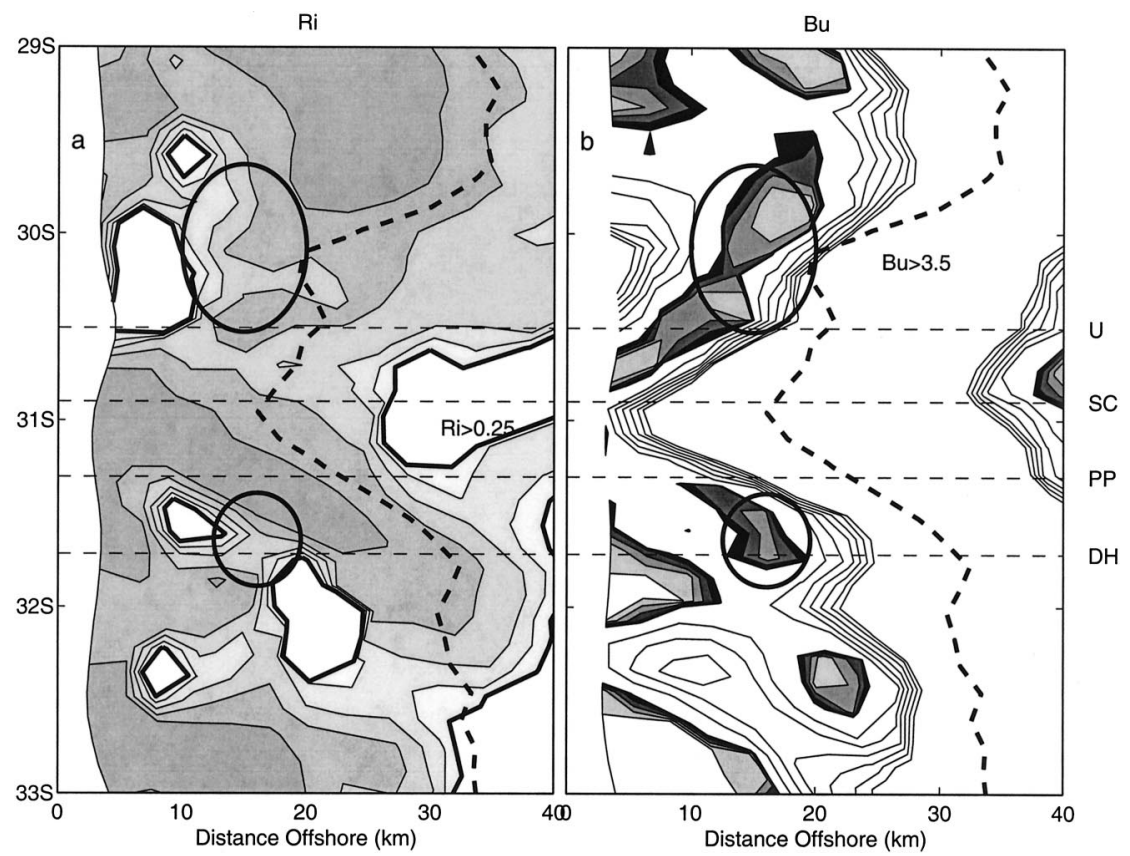

FIG. 10. (a) The Richardson number ( $\mathrm{Ri})(\mathrm{CI}=0.05, \max =0.25)$ and (b) the slope Burger number $B_{u}(C I=0.5, \max =3)$. Shaded contours represent lower values $\mathrm{Ri}<0.25$ and $B_{u}<$ 0.2). The geometric depiction is as in Fig. 8.

mediately south of Smoky Cape) where concentrations of up to $5 \mathrm{mg} \mathrm{m}^{-3}$ were observed.

The maximum chlorophyll- $a$ concentration (i.e., phytoplankton accumulation) is typically found along the $25.25 \sigma_{\theta}$ isopycnal. This suggests that the organisms flourish in water of this density, aided perhaps by adequate nutrient and light concentrations (Jeffrey and Hallegraeff 1990). This relationship between phytoplankton concentration and density motivates the use of the $25.25 \sigma_{\theta}$ isopycnal as an indicator of where the maximum concentrations of nutrient or phytoplankton may be found.

To this end we calculate the mean velocities along the $25.25 \sigma_{\theta}$ isopycnal surface. A weighted average of the velocity above and below the isopycnal is used to calculate the actual velocity along the isopycnal surface. The depth of the isopycnal and the thickness of the slab are also calculated. The maximum thickness of the isopycnal slab is $25 \mathrm{~m}$ thick and the mean thickness across the domain is $9.5 \mathrm{~m}$. The velocity field along the 25.25 $\sigma_{\theta}$ surface and the depth of the isopycnal are shown in Fig. 12. The maximum depth of the isopycnal is $175 \mathrm{~m}$ in the north of the domain. Between Smoky Cape and Port Stephens the $25.25 \sigma_{\theta}$ isopycnal is found at a depth of 50-75 $\mathrm{m}$ in the EAC jet, at a distance of $20-40 \mathrm{~km}$ offshore where the maximum velocity is $\sim 1.5 \mathrm{~m} \mathrm{~s}^{-1}$. This isopycnal is uplifted to the surface in the coastal waters to the south of Smoky Cape and toward the south of the domain.

\section{b. Particle advection: Backward in time}

To address the fundamental question-from where does the upwelled water come?- the advection of particles is examined in a reverse fashion along the 25.25 $\sigma_{\theta}$ isopycnal surface. Particles are released in two directions, alongshore and across-shore at $t=0$ and then advected backward in time for 10 days $(t=-10)$.

\section{1) Alongshore release}

First, particles are released shore-parallel extending the length of the coast at various distances from land. The trajectories of particles that are advected backward along the $25.25 \sigma_{\theta}$ isopycnal from the three release distances $(\mathrm{Rd}=9.5,31$, and $44 \mathrm{~km}$ from the coast) are displayed in Fig. 13 (top).

At a distance of $9.5 \mathrm{~km}$ from the coast nearly all particles originate immediately upstream, indicating simple southward advection parallel to the coast. Particle trajectories farther offshore indicate that particles are entrained into the EAC from the coastal waters, with many of the particles undergoing initial northward movement before being caught up in the strong southward flow. At the farthest distance from the coast north of Smoky Cape there is evidence of entrainment from inshore, as well as onshore flow eastward of the jet and subsequent southward advection. South of Smoky Cape, both entrainment and advection occurs, as well as coastal recirculation. These trajectory experiments reveal that particles upwelled to the coastal waters at Smoky Cape 


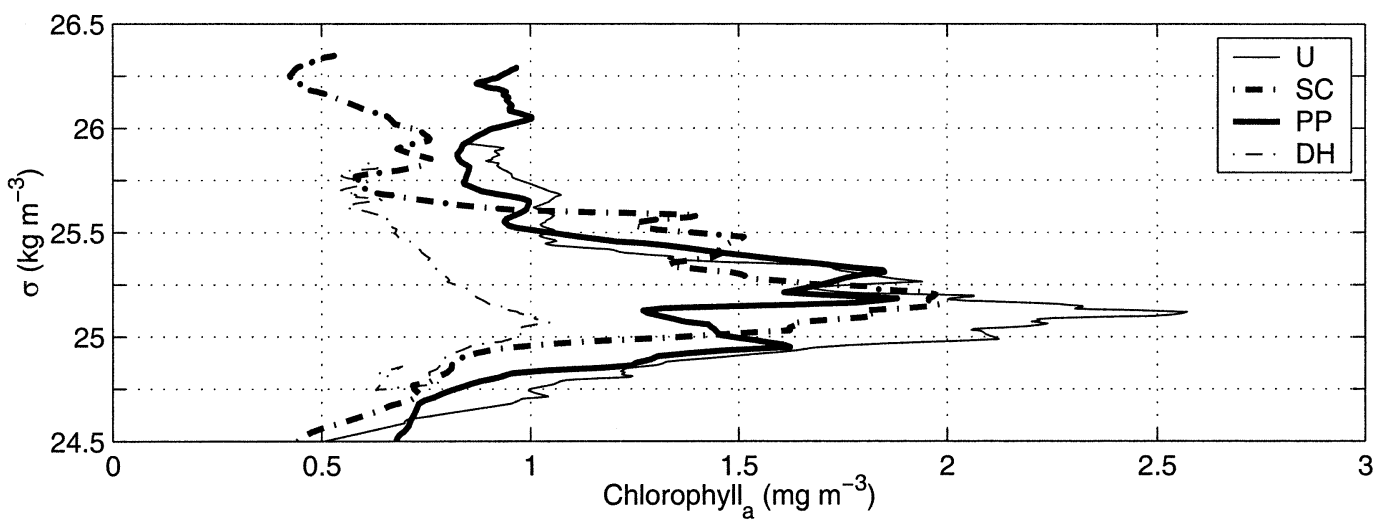

FIG. 11. Mean chlorophyll- $a$ concentrations $\left(\mathrm{mg} \mathrm{m}^{-3}\right)$ vs potential density $\left(\sigma, \mathrm{kg} \mathrm{m}^{-3}\right)$ as measured at Urunga (U), Smoky Cape (SC), Point Plomer (PP), and Diamond Head (DH) during Nov 1998.

would be advected to Port Stephens within 5 days. The isopycnal trajectories show that uplift from depth and subsequent entrainment play an important role along the isopycnal surface. North of Smoky Cape, uplift is occurring from eastward of the jet and entrainment from inshore of the jet. Furthermore, at each of the offshore distances, there is a recirculation found to the north of Port Stephens centered around $32^{\circ} 30^{\prime} \mathrm{S}$.

To the north of Smoky Cape particles that are found offshore are uplifted from $175 \mathrm{~m}$ to a depth of less than $100 \mathrm{~m}$ and are then advected southward. The observations show an increase in the concentrations of nutrient in the surface waters at Smoky Cape and subsequent alongshore advection toward Point Plomer, where chlorophyll- $a$ concentrations are seen to increase (Fig. 11). Thus plankton and nutrients traveling along the $25.25 \sigma_{\theta}$ isopycnal surface are in due course raised into the euphotic zone, where photosynthesis can occur more effectively.

\section{2) ACROSS-SHORE RELEASE}

The second method involved seeding particles along transects aligned perpendicular to the coast. Three shore normal transects varying with latitude are presented in Fig. 13 (bottom). The transects show that alongshore advection plays an increasing role southward of Smoky Cape. At the northern most section (north of Smoky Cape) the particles travel less than $180 \mathrm{~km}$ in the 10 day period, whereas farther to the south, some of the particles that arrive at Port Stephens travel well over $400 \mathrm{~km}$. These particles are obviously caught up in the main EAC jet and are advected rapidly. At the northern sections, many of the particles are uplifted from depth
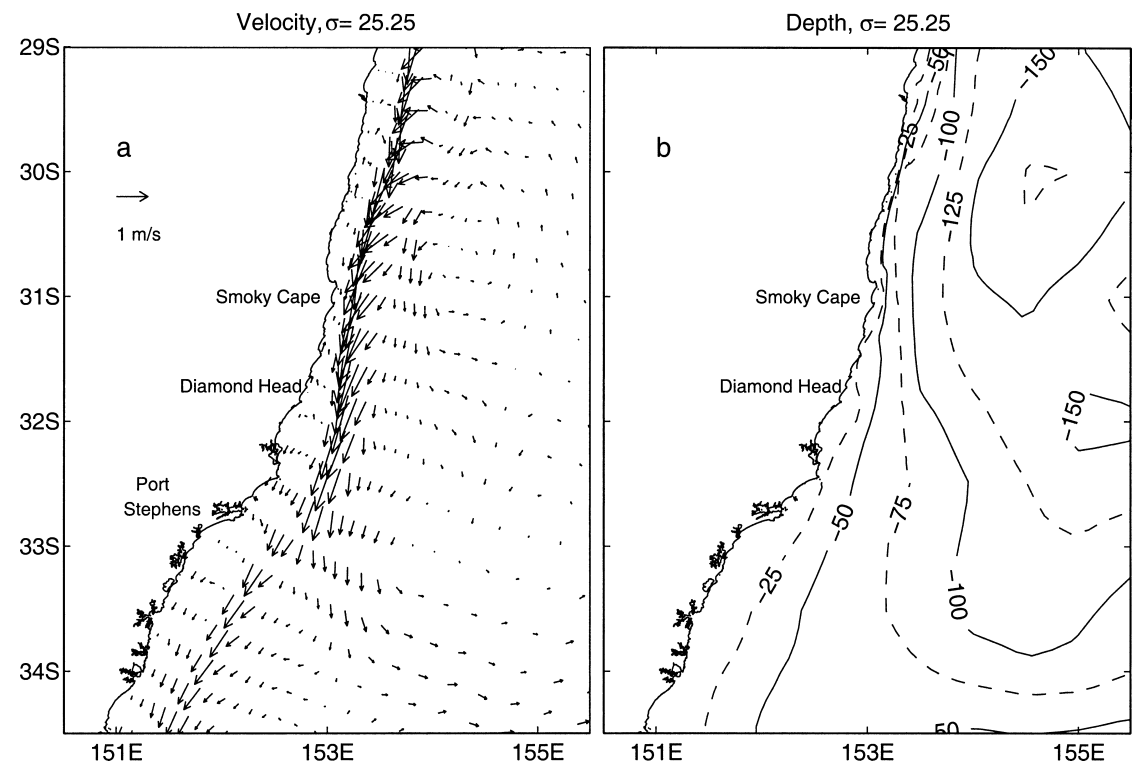

FIG. 12. (a) The velocity field and (b) the depth of the $25.25 \sigma_{\theta}$ isopycnal. 
Isopycnal trajectory $\sigma=25.25$
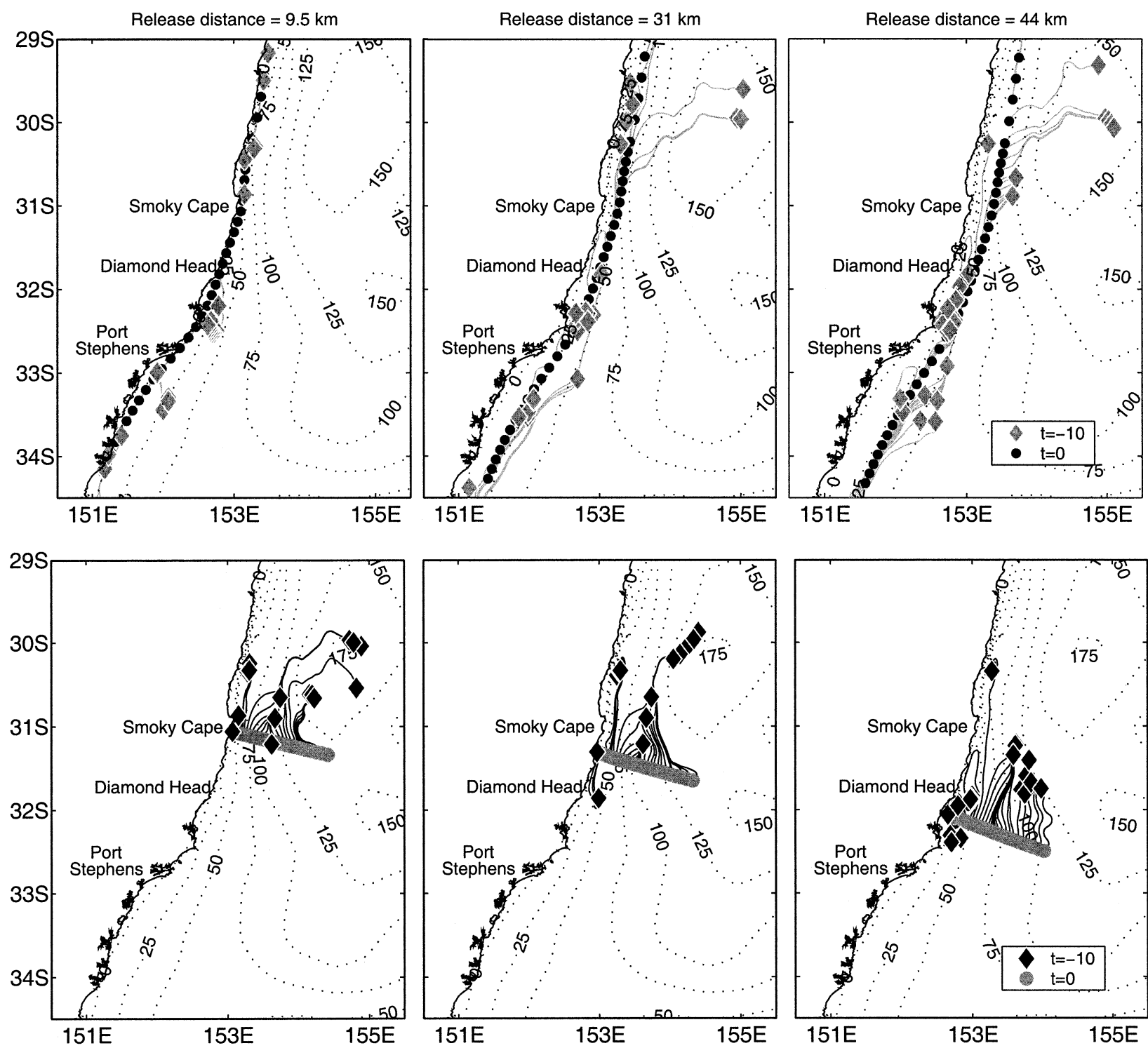

FIG. 13. Trajectories of particles advected backward in time along the $25.25 \sigma_{\theta}$ isopycnal. (top) Particles released parallel to the coast at three offshore distances and (bottom) particles released perpendicular to the coast at three different latitudes. The release position $(t=0)$ is indicated by filled circle ( ). The particles are advected backwards from their final position for 10 days $(t=-10)$ to the particle origin, which is indicated by filled diamond $(\checkmark)$. The depth of the isopycnal is indicated by the dotted contours. The particle paths indicate where upwelled water may have originated.

with the isopycnal, the depth of which is indicated by the dotted contours. Across the southern sections between Diamond Head and Port Stephens the particles originate in shallower water. The sections south of Smoky Cape clearly show that particles that are found inshore actually originate farther to the south and are advected northward by the inshore counter current. The particles that move northward travel at a much slower rate and show evidence of a cyclonic recirculation.

Biologically the implications of this study are important. Retention in a recirculating eddy allows greater utilization of the nutrient by photosynthetic organisms such as phytoplankton, as it increases the residence time in any one location. Moreover, the presence of a cyclonic eddy is likely to enhance upwelling through Ekman pumping and if the nutrient-rich water is persistently being brought toward the surface then algal blooms are able to develop frequently, as seen in Fig. 1 , thus enhancing growth of zooplankton and larval fish.

Further experiments tracking particles forward in time showed the transport of surface waters from Smoky Cape farther south, and two scenarios are evident (not 
shown). While the main EAC flow separates from the coast and flows offshore into the Tasman Sea, there is also clear evidence of continued transport $500 \mathrm{~km}$ southward in coastal and continental shelf waters as far as Sydney. The climatology is an average, and concurrently shows scenarios that are normally separate and distinct. However, this transport of tropical EAC waters into southern coastal regions explains the biological connectivity occasionally observed along the NSW coast southward of the EAC separation point (e.g., Delacruz et al. 2003).

\section{Summary}

The primary aims of this study are to gain insight into the climatological oceanographic conditions and flow dynamics prevalent in the waters off the NSW coast and to investigate the origin of upwelled water. The POM is initialized with the mean climatological temperature and salinity records obtained from CARS and forced across the northern boundary with a calculated geostrophic velocity field. While there was no specific intention to simulate actual observations, the simulated current fields compare favorably with the observations of Roughan and Middleton (2002) both upstream and downstream of the EAC separation point.

Dynamical investigations demonstrate that nonlinearities are important in the EAC system, particularly in the separation region where the flow shifts from alongshore acceleration north of the separation point to across-shore adjustment south of the separation point where $U V_{x}$ and $V V_{y}$ change in sign. Associated with this is an increase in bottom stress downstream of the separation point allowing for an increase in Ekman pumping through the BBL. Coincident with this is a region of subcritical Ri and low $B_{u}$, conducive to the maintenance of an active BBL and a region of prevalent divergence across the continental shelf south of Smoky Cape. All of these factors potentially contribute to the regular upwelling observed in the region.

Particle-tracking experiments forced by velocities along the $25.25 \sigma_{\theta}$ isopycnal (indicative of waters high in chlorophyll $a$ ) demonstrate that upwelled water off Smoky Cape can originate to the north and well offshore between $29^{\circ}$ and $31.5^{\circ} \mathrm{S}$. Additionally, the particle-tracking experiments demonstrate that particles originating adjacent to the coast south of Smoky Cape typically flow northward before becoming entrained into the EAC jet. Phytoplankton blooms have historically been observed in this region (Rochford 1975; Hallegraeff and Jeffrey 1993). However, in contrast to previous ideas, the present work shows that although algal blooms observed in this region may have originated to the north at Smoky Cape, it is also possible that they were advected northward from Diamond Head. The relationship between nutrient concentrations and the development of phytoplankton and zooplankton blooms in the EAC en- vironment is not well documented and thus could form the basis for future work.

Acknowledgments. Thanks go to all who assisted in the development of the NSW shelf model and two anonymous reviewers who gave many useful suggestions on earlier versions of the manuscript. We thank CSIRO Marine Research for permission to use CARS data and their supply of SST and SeaWifs images. The ANU supercomputing facility (APAC) was used for all numerical simulations. This work was supported by the Australian Research Council.

\section{REFERENCES}

Blumberg, A. F., and G. L. Mellor, 1987: A description of a threedimensional coastal ocean circulation model. Three-Dimensional Coastal Ocean Models, N. S. Heaps, Ed., Coastal and Estuarine Sciences, Vol. 4, Amer. Geophys. Union, 1-16.

Boland, F. M., and B. V. Hamon, 1970: The East Australian Current 1965-1968. Deep-Sea Res., 17, 777-794.

Cresswell, G. R., C. Ellyett, R. Legeckis, and A. F. Pierce, 1983: Nearshore features of the East Australian Current System. Aust. J. Mar. Freshwater Res., 34, 105-114.

Delacruz, J., J. H. Middleton, and L. M. Suthers, 2003: Population growth and transport of the red tide dinoflagellate Noctiluca scintillans in the coastal waters off Sydney, Australia, using cell diameter as a tracer. Limnol. Oceanogr., 48, 656-674.

Garrett, C., P. MacCready, and P. Rhines, 1993: Boundary mixing and arrested Ekman layers. Rotating stratified flow near a sloping boundary. Annu. Rev. Fluid. Mech., 25, 291-323.

Gibbs, M. T., P. Marchesiello, and J. H. Middleton, 1997: Nutrient enrichment of Jervis Bay, Australia during the massive 1992 coccolithophorid bloom. Mar. Freshwater Res., 48, 473-478.

Godfrey, J. S., G. R. Cresswell, and F. M. Boland, 1980: Observations of low Richardson numbers and undercurrents near a front in the East Australian Current. J. Phys. Oceanogr., 10, 301-307.

Hallegraeff, G. M., and S. W. Jeffrey, 1993: Annually recurrent Diatom blooms in spring along the New South Wales coast of Australia. Aust. J. Mar. Freshwater Res., 44, 325-34.

Jeffrey, S. W., and G. M. Hallegraeff, 1990: Phytoplankton ecology of Australasian waters. Biology of Marine Plants, M. Clayton and R. King, Eds., Longman Cheshire, 310-348.

Marchesiello, P., and J. H. Middleton, 2000: Modeling the East Australian Current in the Western Tasman Sea. J. Phys. Oceanogr., 30, 2956-2971.

- M. T. Gibbs, and J. H. Middleton, 2000: Simulations of coastal upwelling on the Sydney continental shelf. Aust. J. Mar. Freshwater Res., 51, 577-588.

Mata, M. M., M. Tomczak, S. Wijffels, and J. A. Church, 2000: East Australian current volume transports at $30^{\circ} \mathrm{S}$ : Estimates from the World Ocean Circulation Experiment hydrographic sections PR11/P6 and the PCM3 current meter array. J. Geophys. Res., 105, 28 509-28 526.

Mellor, G. L., 1991: An equation of state for numerical models of oceans and estuaries. J. Atmos. Oceanic Technol., 8, 608-611. -, 1996: User's guide for a three-dimensional, primitive equation, numerical ocean model. Program in Atmospheric and Oceanic Sciences, Princeton University Technical Report, Princeton, NJ, 38 pp.

Oke, P. R., and J. H. Middleton, 2000: Topographically induced upwelling off eastern Australia. J. Phys. Oceanogr., 30, 512-531.

, and - 2001: Nutrient enrichment off Port Stephens: The role of the East Australian Current. Cont. Shelf Res., 21, 587606.

_, M. H. England, and J. H. Middleton, 2003: On the dynamics 
of an observed thermal front off central eastern Australia. $J$. Geophys. Res., 108, 3106, doi:10.1029/2002JC001370.

Reid, J. L., and A. W. Mantyla, 1976: The effect of the geostrophic flow upon coastal sea elevations in the northern North Pacific Ocean. J. Geophys. Res., 81, 31 300-31 310.

Ridgway, K. R., and J. S. Godfrey, 1994: Mass and heat budgets in the East Australian Current: A direct approach. J. Geophys. Res., 99, 3231-3248.

- and _ 1997: Seasonal cycle of the East Australian Current. J. Geophys. Res., 102, 22 921-22 936.

—_, J. R. Dunn, and J. L. Wilkin, 2002: Ocean interpolation by four-dimensional weighted least squares-Application to the waters around Australasia. J. Atmos. Oceanic Technol., 19, 13571375 .

Rochford, D. J., 1975: Nutrient enrichment of East Australian coastal waters. 2. Laurieton upwelling. Aust. J. Mar. Freshwater Res., 26, 233-43.

Roughan, M., and J. H. Middleton, 2002: A comparison of observed upwelling mechanisms off the east coast of Australia. Cont. Shelf Res., 22, 2551-2572.

, and — 2003: The role of the East Australian Current in driving upwelling off central eastern Australia. J. Geophys. Res., in press.

Smagorinsky, J., 1963: General circulation experiments with primitive equations, 1. The basic experiment. Mon. Wea. Rev., 91, 99-164.

Tilburg, C. E., H. E. Hurlburt, J. J. O'Brien, and J. F. Shriver, 2001: The dynamics of the East Australian Current system: The Tasman Front, the East Auckland Current, and the East Cape Current. J. Phys. Oceanogr., 31, 2917-2943. 